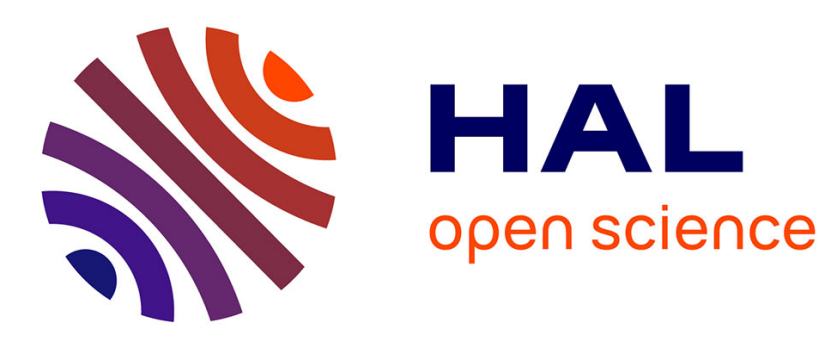

\title{
The COUPLEX Test Cases: Nuclear Waste Disposal Simulation
}

\author{
Alain Bourgeat, Michel Kern, Stephan Schumacher, Jean Talandier
}

\section{To cite this version:}

Alain Bourgeat, Michel Kern, Stephan Schumacher, Jean Talandier. The COUPLEX Test Cases: Nuclear Waste Disposal Simulation. Computational Geosciences, 2004, 10.1023/B:COMG.0000035073.03009.5d . hal-01315461

\section{HAL Id: hal-01315461 \\ https://inria.hal.science/hal-01315461}

Submitted on 13 May 2016

HAL is a multi-disciplinary open access archive for the deposit and dissemination of scientific research documents, whether they are published or not. The documents may come from teaching and research institutions in France or abroad, or from public or private research centers.
L'archive ouverte pluridisciplinaire HAL, est destinée au dépôt et à la diffusion de documents scientifiques de niveau recherche, publiés ou non, émanant des établissements d'enseignement et de recherche français ou étrangers, des laboratoires publics ou privés. 


\title{
The Couplex Test Cases: Nuclear Waste Disposal Simulation
}

\author{
A. Bourgeat (alain.bourgeat@cdcsp.univ-lyon1.fr) \\ MCS, Université Lyon 1, Boulevard Latarjet, 69622 Villeurbanne, France
}

M. Kern (michel.kern@inria.fr)

INRIA, Rocquencourt, BP 105, 78153 Le Chesnay Cedex, France

S. Schumacher (stephan.schumacher@andra.fr) and J. Talandier

(jean.talandier@andra.fr)

Andra, 1-7, rue Jean Monnet, 92298 Châtenay-Malabry, Cedex, France

\begin{abstract}
The models appearing in the COUPLEX benchmark are a set of simplified albeit realistic test cases aimed at simulating the transport of radionuclides around a nuclear waste repository. Three different models were used:

The first test case is related to simulations based on a simplified 2D far-field model close to those used for safety assessments in nuclear waste management. It leads to a classical convection diffusion type problem, but with highly variable parameters in space, highly concentrated sources in space and time, very different time scales and accurate results expected even after millions of years.

The second test case is a simplification of a typical 3D near-field computation, taking into account the glass dissolution of vitrified waste, and the congruent release of several radionuclides (including daughter products), with their migration through the geological barrier.

The aim of the third test case is to use the results of the near-field computation (COUPLEX 2) to drive the behavior of the nuclide source term in the Far Field computation (COUPLEX 1). The modeling of this last case was purposely left rather open, unlike the previous two, leaving the choice to participants of the way the coupling should be made.
\end{abstract}

Keywords: Nuclear waste, numerical simulation, porous media

\section{Introduction}

Deep disposal of nuclear waste raises a number of challenges for numerical simulations : widely differing lengths and time-scales, highly variable physical coefficients and stringent accuracy requirements. It is no wonder therefore if the topic is catching the attention of computational scientists and numerical analysts.

The COUPLEX models are a set of three different test cases, of increasing difficulty.

- The first test case, Couplex 1, is a simplified far-field computation. We have chosen a 2D model, with four geological layers, in order to expose the main numerical difficulties: a highly heterogeneous medium (hydraulic conductivities vary over six orders of magnitude), and a highly

(c) 2004 Kluwer Academic Publishers. Printed in the Netherlands.

couplex.tex; 3/03/2004; 16:37; p.1 
elongated medium (width-to-height ratio is over 30). In this model, the repository is a simple rectangle acting as a distributed source with known time dependency.

- The second test case is a near-field computation, the aim of which is to provide a better description of the source term in the far-field model. We have incorporated more physics than in the previous model, and a 3D geometry has been used, thus ending up with a more difficult case.

- The last test case was deliberately left more open than the previous two. Its aim is to couple the near field and the far field, that is to use the results of COUPLEX 2 to drive a model similar to COUPLEX 1, but this time in 3D.

We emphasize once more that all three test cases are simplified with respect to a real safety simulation, in order to concentrate on the numerical difficulties. In all three cases, they derive their approach from the models used by Andra.

The rest of this paper deals with a definition of some general notation, followed by a detailed description of each each test case in turn. We show the geometry, describe in detail the model-defining equations, and provide the physical parameters to be used.

\subsection{GENERAL TRANSPORT OPERATOR}

Each of the physical models we describe is a variant of a convection-diffusionreaction equation. In order to shorten the equations, we found it useful to define a "general" transport operator as follows, in some spatial domain $R^{*}$ :

$$
L(C)=-\nabla \cdot(\mathbf{D} \nabla C-\mathbf{u} C) \quad \text { in } R^{*} .
$$

The diffusion-dispersion tensor $\mathbf{D}$ is a general anisotropic tensor (see Bear (Bear and Bachmat, 1991; Bear and Verruijt, 1987) ), that is given as a function of the Darcy velocity $\mathbf{u}$ by:

$$
\mathbf{D}=d_{e} I+|\mathbf{u}|\left[\alpha_{l} E(\mathbf{u})+\alpha_{t}(I-E(\mathbf{u}))\right]
$$

with

$$
E_{i j}(\mathbf{u})=\frac{u_{i} u_{j}}{|\mathbf{u}|^{2}} .
$$

For any species or isotope, $d_{e}\left(\mathrm{~m}^{2} / \mathrm{s}\right)$ is the effective diffusion coefficient, $\alpha_{l}$ and $\alpha_{t}$, the longitudinal and transverse dispersion coefficients (both in metres). 


\section{Couplex 1: Far-field Computation}

\subsection{INTRODUCTION}

The repository lies at a depth of $450 \mathrm{~m}$ inside a clay layer located between a layer of limestone and a layer of marl above and a layer of Dogger limestone underneath. Water flows slowly (creeping flow) through those porous media and convects the radioactive materials once the containers start to leak. There is also a dilution effect which, in mathematical terms, is similar to diffusion. The problem raises three main difficulties:

1. The geometry of the domain is highly elongated with a width of $25 \mathrm{~km}$ and a depth of $700 \mathrm{~m}$.

2. The convection and diffusion constants are very different from one layer to another. In the clay layer, for instance, there is almost no convection while, in the other layers, diffusion and convection are both important.

3. Radioelements leak from containers into the clay within a short period compared with the millions of years over which convection and diffusion remain active.

\subsection{GEOMETRY}

In this first test case, the computation is restricted to a $2 \mathrm{D}$ section of the disposal site. Thus, the computational domain lies within a rectangle $O=$ $(0,25000) \times(0,695)$ in metres. The Dogger, clay, limestone, and marl layers are located as follows (starting from the bottom left corner of the rectangle):

- The Dogger constitutes the bottom layer: $0<z<200$;

- The clay lies between the horizontal line $z=200$ and the line from $(0,295)$ to $(25000,350)$;

- The limestone lies between the line from $(0,295)$ to $(25000,350)$ and the horizontal line $z=595$;

- The marl is near the surface : $595<z<695$.

The repository, $\mathcal{R}$, is modeled by a uniform rectangular source in the clay layer:

$$
\mathcal{R}=\{(x, z) \in(18440,21680) \times(244,250)\}
$$

The geometry is summarized on Figure 1. For that domain the computation should be carried for $t \in(0, T)$ with $T=10^{7}$ years. 


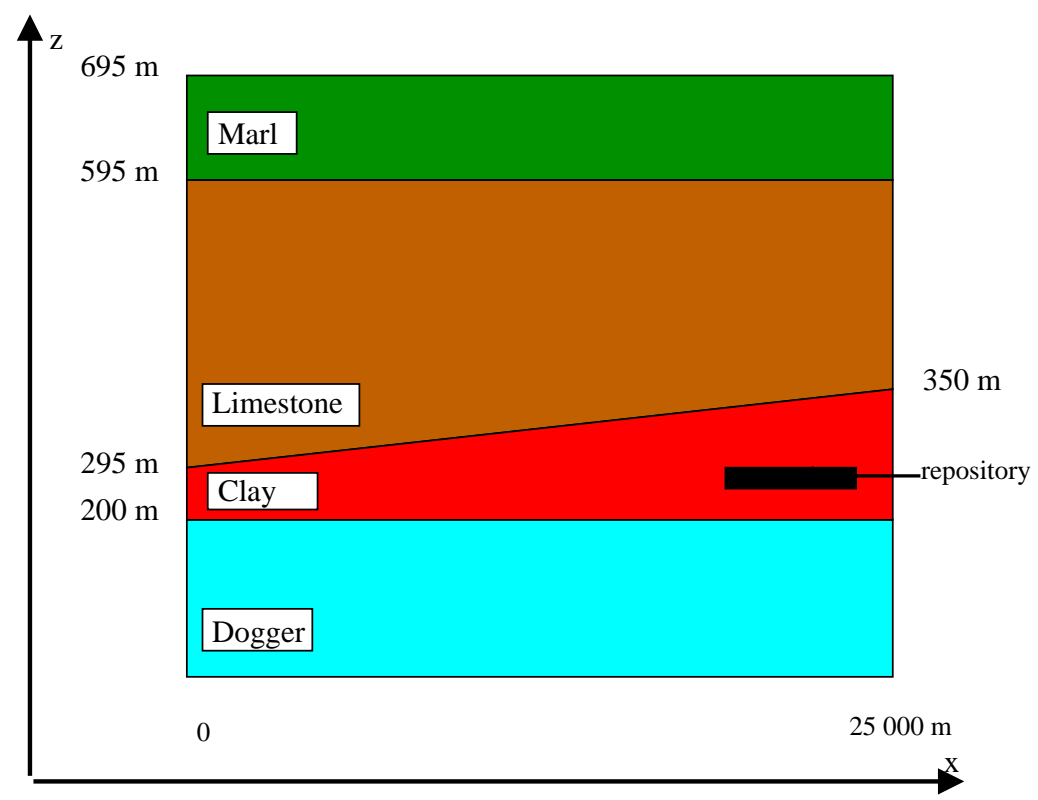

Figure 1. Geometry of computational domain

\subsection{FLOW MODEL}

It is assumed that all rock layers are saturated with water and that boundary loads are stationary so that the flow is independent of time. Darcy's Law gives the velocity $\mathbf{u}$ in terms of the hydro-dynamic load $H=P / \rho g+z$ :

$$
\mathbf{u}=-K \nabla H
$$

where the permeability tensor, $K$, assumed constant in each layer is given in Table I, $P$ is the pressure and $g$ is Newton's constant. Conservation of mass $(\nabla \cdot(\rho u)=0$, with density, $\rho$, assumed constant) implies that

$$
\nabla \cdot(K \nabla H)=0 \quad \text { in } O
$$

Table I. Permeability tensor in the four rock layers

\begin{tabular}{lllll}
\hline & Marl & Limestone & Clay & Dogger \\
\hline$K(\mathrm{~m} /$ year $)$ & $3.153610^{-5}$ & 6.3072 & $3.153610^{-6}$ & 25.2288 \\
\hline
\end{tabular}


Boundary conditions are as follows:
$H=289$
on $\{25000\} \times(0,200), \quad$ (right Dogger)
$H=310$
on $\{25000\} \times(350,595)$,
(right limestone)
$H=180+160 x / 25000$
on $(0,25000) \times\{695\}, \quad$ (top)
$H=200$
on $\{0\} \times(295,595)$,
(left limestone)
$H=286$
on $\{0\} \times(0,200)$
(left Dogger),
$\frac{\partial H}{\partial n}=0$
elsewhere.

\subsection{RadionuClide Migration}

We consider two species of particular interest, iodine 129 and plutonium 242. Both escape from the repository cave into the water and their concentrations $C_{i}, i=1,2$ are given by two independent convection-diffusion equations:

$$
R_{i} \omega \frac{\partial C_{i}}{\partial t}+L\left(C_{i}\right)+R_{i} \omega \lambda_{i} C_{i}=f_{i} \quad \text { in } O \times(0, T) \quad i=1,2 .
$$

where $L$ is the general transport operator, as defined in section 1.1, and

- $R_{i}$, the latency retardation factor, with value 1 for ${ }^{129} \mathrm{I}, 10^{5}$ for ${ }^{242} \mathrm{Pu}$ in the clay and 1 elsewhere for both iodine and plutonium;

- The effective porosity, $\omega$, is equal to 0.001 for ${ }^{129} \mathrm{I}, 0.2$ for ${ }^{242} \mathrm{Pu}$ in the clay layer and 0.1 elsewhere for both;

$-\quad \lambda_{i}=\log 2 / T_{i}$ where $T_{i}$ is the half-life of the element : $T_{1}=1.5710^{7}$ for ${ }^{129} \mathrm{I}, T_{2}=3.7610^{5}$ for ${ }^{242} \mathrm{Pu}$ (in years);

- The effective diffusion/dispersion tensors, $\mathbf{D}_{i}$, have been defined in (2) and (3) above. The coefficients are assumed constant in each layer and are given in Table II.

In this test case, the values of the source terms, $f_{i},(i=1,2)$, in the repository $\mathcal{R}$ are given in tabulated form in separate data files. The source terms are assumed to be spatially uniformly spread out in all the repository $\mathcal{R}$. It is assumed that there is no source outside the repository $\left(f_{i},(i=1,2)\right.$ in $\left.O \backslash \overline{\mathcal{R}}\right)$. The dependence in time is shown in Figure 2. The structure of the data file is described in Appendix A. 
Table II. Dispersion coefficients for the radioelements in the four layers

\begin{tabular}{|c|c|c|c|c|c|c|}
\hline & \multicolumn{3}{|c|}{ Iodine } & \multicolumn{3}{|c|}{ Plutonium } \\
\hline & $d_{e}\left(\mathrm{~m}^{2} /\right.$ year $)$ & $\alpha_{L}(\mathrm{~m})$ & $\alpha_{T}(\mathrm{~m})$ & $d_{e}\left(\mathrm{~m}^{2} /\right.$ year $)$ & $\alpha_{L}(\mathrm{~m})$ & $\alpha_{T}(\mathrm{~m})$ \\
\hline Dogger & $5.010^{-4}$ & 50 & 1 & $5.010^{-4}$ & 50 & 1 \\
\hline Clay & $9.4810^{-7}$ & 0 & 0 & $4.4210^{-4}$ & 0 & 0 \\
\hline Limestone & $5.010^{-4}$ & 50 & 1 & $5.010^{-4}$ & 50 & 1 \\
\hline Marl & $5.010^{-4}$ & 0 & 0 & $5.010^{-4}$ & 0 & 0 \\
\hline
\end{tabular}
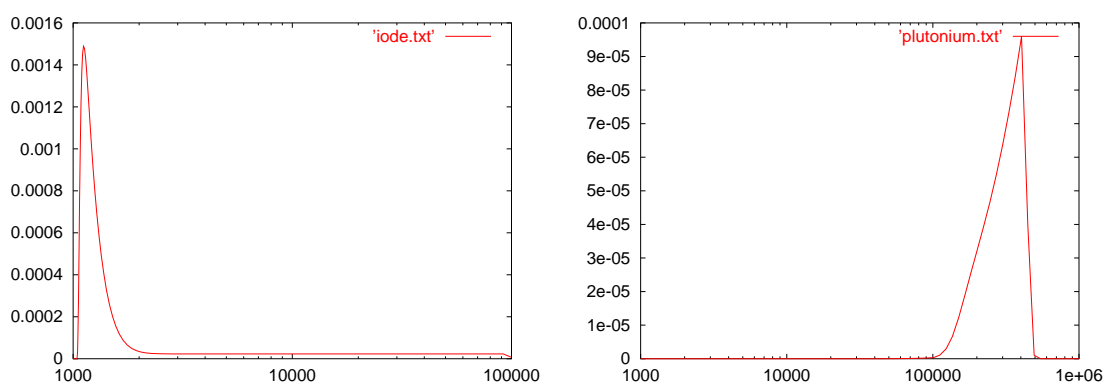

Figure 2. Release of iodine and plutonium as a function of time

\subsection{INITIAL AND BOUNDARY CONDITIONS}

We call time zero the time when containers begin to leak and the radioelements to spread, hence the initial values of the concentration $C_{i}$ are zero at time zero.

Boundary conditions for the transport of any radionuclide $i=1,2$ are

$$
\begin{aligned}
& \frac{\partial C_{i}}{\partial n}=0 \quad \text { on }\{0\} \times(295,595) \quad \text { left limestone } \\
& \frac{\partial C_{i}}{\partial n}=0 \quad \text { on }\{0\} \times(0,200) \quad \text { left Dogger } \\
& \mathbf{D}_{i} \nabla C_{i} \cdot \mathbf{n}-C_{i} \mathbf{u} \cdot \mathbf{n}=0 \quad \text { on }(0,25000) \times\{0\} \quad \text { bottom } \\
& C_{i}=0 \quad \text { elsewhere on the boundary. }
\end{aligned}
$$

where $\mathbf{n}$ is the outward normal to $O$.

\subsection{OUTPUT REQUIREMENTS}

The following output quantities are expected from the simulations(both tables and graphical representations): 
- Contour levels of $C_{i}$ at times 200, 10110, 50110, $10^{6}, 10^{7}$ years (the following levels should be used: $10^{-12}, 10^{-10}, 10^{-8}, 10^{-6}, 10^{-4}$ );

- Pressure field (10 values uniformly distributed between 180 and 340);

- Darcy velocity field, along the three vertical lines given by $x=50, x=$ 12500, $x=20000$, using 100 points along each line;

- Places where the Darcy velocity is zero;

- Cumulative total fluxes through the top and the bottom clay layer boundaries, as a function of time;

- Cumulative total fluxes through the left boundaries of the Dogger and limestone layers;

- The discretization grid of the domains and the time stepping used in the simulations should also be provided.

\section{Couplex 2: Near-field Computation}

\subsection{INTRODUCTION}

A real repository is made up of a very large number of disposal modules, each of which includes a large number of cells, linked by a backfilled drift. Since modeling all the details of such a repository still presents difficulties, we follow a usual approach in safety computations: we only consider an "elementary cell", and we add periodicity conditions on the boundaries. That last assumption is valid provided there is a large enough number of similar cells in a disposal module, and that the module boundary layer effects are negligible.

The computation in this test case is based on the modeling of three cells linked by a backfilled drift embedded into a homogeneous medium. The dissolution of glass, the ensuing congruent emission of radionuclides, and precipitation of elements with several isotopes are included in the model.

\subsection{GEOMETRY AND FLOW MODEL}

We choose the geometry of the elementary cell to be simple and the host geological medium to be simply made up of the clay layer into which the repository is embedded.

We describe below the elementary cell by successive zooms. The domain ("elementary cell") is a parallelepiped $\mathcal{R}^{*}$, containing three cells and a backfilled drift. Each cell is made up of the container (in this case, a glass parallelepiped, containing the radioactive waste), a buffer and a seal. 


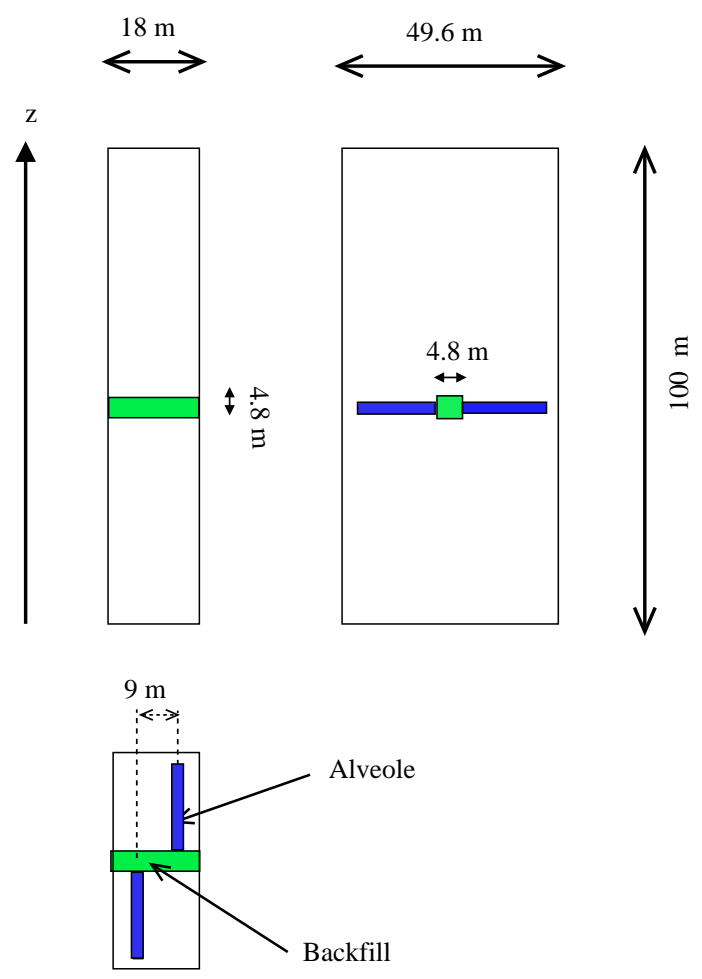

Figure 3. Details of the simulation domain $R^{*}$, (left, front and top views) including the host geological medium, the backfilled drift and the cell

Figure 3 shows global views of the whole domain $\mathcal{R}^{*}$, while Figure 4 presents a close-up view of the backfilled drift with three cells, and Figure 5 provides a detailed view of one cell.

We assume once again that the flow follows Darcy's Law, so that the piezometric head and the Darcy velocity satisfy Equations (4) and (5) above.

The boundary conditions are

- $\quad H$ is given on both horizontal sides of $R^{*}$. The difference in piezometric head is taken equal to $50 \mathrm{~m}$;

- Since the container is impervious, the boundary condition on the container boundary is no-flow: $\frac{\partial H}{\partial n}=0$ there;

- $\quad H$ is supposed to be periodic on the four vertical sides of $R^{*}$ (in order to simulate an entire disposal module). 


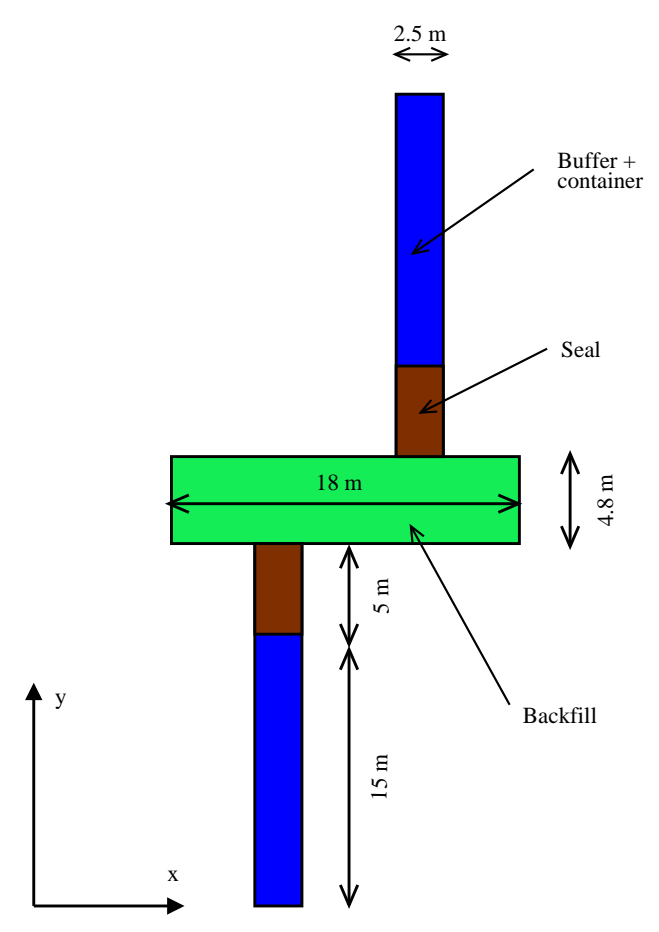

Figure 4. Backfilled drift and three cells included in the host geological medium

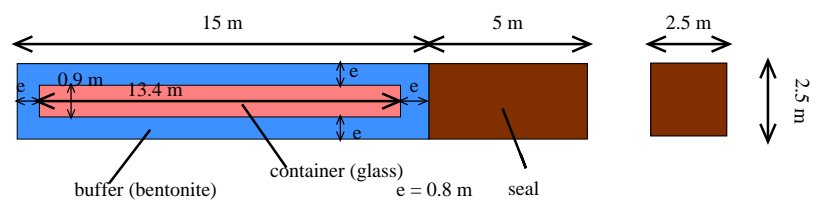

Figure 5. Dimensions of a cell

\subsection{SiliCA MIGRATION (GLASS DISSOLUTION)}

Silica migration is described by a convection-diffusion-reaction type equation:

$$
\phi R_{s} \frac{\partial C_{s}}{\partial t}+L_{s}\left(C_{s}\right)=\rho_{p} \frac{v_{p}}{\lambda_{p}}\left(1-\frac{C_{s}}{S_{p}}\right) \quad \text { in } R^{*} \backslash \bar{C},
$$

where $\phi$ is the porosity, and the retardation factor $R_{S}$ is given by the following equation, ( $\rho_{\mathrm{s}}$ being the density of the solid phase and the distribution coefficient, $K_{d_{s}}$, taking adsorption into account in a simplified way):

$$
R_{s}=1+\rho_{\mathrm{s}} \frac{1-\phi}{\phi} K_{d s} .
$$

We have denoted by 
- $\rho_{p}$ : the precipitate concentration $\left(4.210^{4} \mathrm{~mole} / \mathrm{m}^{3}\right)$;

- $v_{p}$ : the precipitation speed $\left(610^{-9} \mathrm{~m} /\right.$ year $)$;

$-\lambda_{p}$ : the inverse of specific surface (between $810^{-10} \mathrm{~m}$ and $10^{-3} \mathrm{~m}$ );

$-S_{p}$ : the solubility of the precipitated phase $\left(5.410^{-1} \mathrm{~mol} / \mathrm{m}^{3}\right)$.

Silica precipitation follows a first order kinetic law.

We propose two different models for glass dissolution. A detailed model of glass dissolution follows a first order kinetic law. The complete free boundary model associated with the dissolution of the container $C$ is simplified into a Fourier boundary condition on $\partial \mathcal{C}$, the glass-bentonite interface assuming that this interface remains fixed:

$$
-\mathbf{D}_{s} \frac{\partial C_{s}}{\partial n}=\rho_{m} v_{m}\left(1-\frac{C_{s}}{S_{m}}\right), \quad \text { on } \partial C
$$

where we have set:

- $v_{m}$ to be the initial dissolution velocity $\left(1.510^{-5} \mathrm{~m} /\right.$ year $)$;

- $\rho_{m}$, the available concentration that may be dissolved in the matrix $\left(4.210^{3}\right.$ $\left.\mathrm{mol} / \mathrm{m}^{3}\right)$;

- $S_{m}$, the maximum silica concentration (or saturated silica concentration), $\left(8.210^{-1} \mathrm{~mole} / \mathrm{m}^{3}\right)$.

Alternatively, a simplified model of glass dissolution could be used, reduced to a known constant flux on the glass-bentonite interface:

$$
-\mathbf{D}_{s} \frac{\partial C_{s}}{\partial n}=\tau, \quad \text { on } \partial C
$$

with the release factor $\tau=10^{-2} \mathrm{~mol} / \mathrm{m}^{2} /$ year. It should be noted that this simplification will in turn make the congruent emission of radionuclides simpler in Equation (19) in Section 3.4 below.

The initial silica concentration is considered to be equal to its reference value in the geologic medium, that is $9.910^{-5}$ mole/l. The boundary and interface conditions are :

- On the container boundaries, the condition is that given in Equation (8) above;

- $C_{s}=0$ on the top and bottom boundaries of $R^{*}$;

- Periodic boundary conditions on the four outer vertical sides of $R^{*} \backslash \bar{C}$. 


\subsection{RADIONUCLIDE MIGRATION}

We take into account one isolated radionuclide, caesium 135, and two radionuclide chains: ${ }^{238} \mathrm{Pu} \rightarrow{ }^{234} \mathrm{U}$ and ${ }^{242} \mathrm{Pu} \rightarrow{ }^{238} \mathrm{U}$. Those choices allows us to study the precipitation of each element. The half-lives involved are:

Table III. Radionuclide half-lives

\begin{tabular}{rccccc}
\hline Isotope & ${ }^{135} \mathrm{Cs}$ & ${ }^{238} \mathrm{Pu}$ & ${ }^{234} \mathrm{U}$ & ${ }^{242} \mathrm{Pu}$ & ${ }^{238} \mathrm{U}$ \\
\hline Period (years) & $2.310^{6}$ & 87.74 & $2.4510^{5}$ & $3.7610^{5}$ & $4.4710^{9}$ \\
\hline
\end{tabular}

To make writing the equations easier, we associate to each radionuclide an index $k$, which will take the values $k=s, 0,1,2,-1,-2$, as shown in Table IV.

Table IV. Radionuclide-Index association

\begin{tabular}{cccccc}
\hline isotope & ${ }^{135} \mathrm{Cs}$ & ${ }^{238} \mathrm{Pu}$ & ${ }^{234} \mathrm{U}$ & ${ }^{242} \mathrm{Pu}$ & ${ }^{238} \mathrm{U}$ \\
\hline index $k$ & 0 & 1 & -1 & 2 & -2 \\
\hline
\end{tabular}

For $k=1$ or $k=2$, element $k$ is by definition the parent of element $-k$. Isotope -1 and -2 correspond to the same chemical element, as isotopes 1 and 2 do.

Each radionuclide satisfies a convection-diffusion-reaction equation analogous to Equation (7), obviously with an added radioactive decay term. It may possibly precipitate.

\subsubsection{Caesium}

As far as caesium (index $k=0$ ) is concerned, we shall assume that adsorption follows a Langmuir isotherm, and that the solubility limit is so high that caesium does not precipitate. Following Equation (2), the corresponding transport equation becomes:

$$
\phi \frac{\partial}{\partial t}\left(R_{0} C_{0}\right)+L_{0}\left(C_{0}\right)+\phi R_{0} \lambda_{0} C_{0}=0 \quad \text { in } R^{*} \backslash \bar{C}
$$

where the retardation factor now depends on the concentration:

$$
R_{0}=1+\rho_{\mathrm{s}} \frac{1-\phi}{\phi} K_{d_{0}}
$$


through the (concentration dependent) distribution coefficient:

$$
K_{d_{0}}=\frac{\kappa \mathrm{CEC}}{1+\kappa C_{0}} .
$$

In the previous equation, $\kappa=150(\mathrm{~mol} / \mathrm{l})^{-1}$ and CEC is the cationic exchange capacity $(\mathrm{CEC}=80 \mathrm{mmol} / 100 \mathrm{~g})$.

\subsubsection{Plutonium and uranium}

On the contrary, since Plutonium and Uranium may precipitate, we introduce the concentration of the solid phase, denoted by $F_{k}, k=-2,-1,1,2$. The transport of each isotope is described by the following equations:

- For $k=1$ and 2 (plutonium):

$$
\begin{array}{cc}
\rho \phi R_{k} \frac{\partial C_{k}}{\partial t}+\rho L_{k}\left(C_{k}\right)+\rho \phi R_{k} \lambda_{k} C_{k}=\rho \phi S_{k} & \text { in } R^{*} \backslash \overline{\mathcal{C}} \\
\rho_{\mathrm{s}}(1-\phi) \frac{\partial F_{k}}{\partial t}+\rho_{\mathrm{s}}(1-\phi) \lambda_{k} F_{k}=-\phi S_{k} & \text { in } R^{*} \backslash \overline{\mathcal{C}}
\end{array}
$$

- For $k=-1$ and -2 (uranium):

$$
\begin{gathered}
\begin{aligned}
\rho \phi R_{k} \frac{\partial C_{k}}{\partial t}+\rho L_{k}\left(C_{k}\right)+\rho \phi R_{k} \lambda_{k} C_{k}-\rho \phi R_{-k} \lambda_{-k} C_{-k}= \\
=\rho \phi S_{k} \quad \text { in } R^{*} \backslash \overline{\mathcal{C}}
\end{aligned} \\
\rho_{\mathrm{s}}(1-\phi) \frac{\partial F_{k}}{\partial t}+\rho_{\mathrm{s}}(1-\phi) \lambda_{k} F_{k}-\rho_{\mathrm{s}}(1-\phi) \lambda_{-k} F_{-k}=-\phi S_{k} \quad \text { in } R^{*} \backslash \overline{\mathcal{C}}
\end{gathered}
$$

In Equations (13) to (16), the retardation factor, $R_{k}$, is still given by an isotherm similar to Equation (11):

$$
R_{k}=1+\rho_{\mathrm{s}} \frac{1-\phi}{\phi} K_{d k}
$$

but with a constant coefficient, $K_{d k}$.

In Equations (13) to (16), the dissolution-precipitation term, $S_{k}$, takes into account the precipitation per species, by assuming that each isotope precipitates proportionally to its mass concentration. The dissolution-precipitation term is given by:

$$
S_{k}= \begin{cases}\sigma\left(C_{k}-C_{k}^{\mathrm{sat}}\right) & \text { if } C_{k}^{\mathrm{sat}} \leq C_{k} \\ 0 & \text { if } C_{k} \leq C_{k}^{\mathrm{sat}} \text { and } F_{k}=0\end{cases}
$$


with:

$$
C_{k}^{\mathrm{sat}}=C_{e(k)}^{\mathrm{sat}} \frac{\phi R_{k} C_{k}+\rho_{\mathrm{s}}(1-\phi) F_{k}}{\sum_{\substack{\left|k^{\prime}\right|=1,2 \\ k^{\prime} \text { has same } \\ \text { sign as } k}}\left(\phi R_{k^{\prime}} C_{k^{\prime}}+\rho_{\mathrm{s}}(1-\phi) F_{k^{\prime}}\right)},
$$

where $C_{e}^{\text {sat }}$ is the solubility limit of the considered species, $e \in\{\mathrm{Pu}, \mathrm{U}\}$, with $e(1)=e(2)=\mathrm{Pu}, e(-1)=e(-2)=\mathrm{U}$, and $\sigma=10^{4}$ year $^{-1}$.

The dissolution of glass generates a congruent emission of the radionuclides still present in the waste. Taking into account the radioactive decay of the radionuclides leads to a boundary condition with time-dependent coefficients:

$$
\mathbf{D}_{k} \frac{\partial C_{k}}{\partial n}=\frac{N_{k}(t)}{N_{s}^{0}} \mathbf{D}_{s} \frac{\partial C_{s}}{\partial n}, \quad k=-1,1,0,1,2
$$

on the glass-bentonite interface $\partial \bar{C}$ (supposed fixed as in Equation (8)). The constant $N_{s}^{0}$ is the initial number of moles of silica in the container, and is equal to $N_{s}^{0}=4.5610^{4}$ (the silica density in the container is equal to the number $\rho_{m}$ which appears in Equation (8)).

It should be noted that in case the simplified model of glass dissolution given in Equation (9) is used, Equation (19) is simplified to:

$$
\mathbf{D}_{k} \frac{\partial C_{k}}{\partial n}=\tau \frac{N_{k}(t)}{N_{s}^{0}}, \quad k=-1,1,0,1,2
$$

with $\tau=10^{-2} \mathrm{~mol} / \mathrm{m}^{2} /$ year.

The functions $N_{k}(t)$ are the number of moles of the corresponding element at time $t$. They are solutions of a coupled set of differential equations expressing the decay of the element under consideration. A simple computation gives the expression for $N_{k}(t)$ :

$$
\begin{gathered}
N_{k}(t)=N_{k}^{0} e^{-\lambda_{k} t}, \quad k=0,1,2 \\
N_{k}(t)=N_{-k}^{0} \frac{\lambda_{-k}}{\lambda_{k}-\lambda_{-k}} e^{-\lambda_{-k} t}+\left(N_{k}^{0}+N_{-k}^{0} \frac{\lambda_{-k}}{\lambda_{-k}-\lambda_{k}}\right) e^{-\lambda_{k} t}, \\
k=-1,-2
\end{gathered}
$$

The constants $N_{k}^{0}$ (initial values of the number of mole for each radionuclide) are given in Table $\mathrm{V}$ below. They were computed from the (known) activities for each radionuclide, as detailed in Appendix B. Those numbers are valid for one cell.

\subsubsection{Initial and boundary conditions}

At the beginning of the simulation, radionuclide concentration is zero everywhere. 
Table V. Initial number of moles for the five radionuclides in one cell

\begin{tabular}{cccccc}
\hline Isotope & ${ }^{135} \mathrm{Cs}$ & ${ }^{238} \mathrm{Pu}$ & ${ }^{234} \mathrm{U}$ & ${ }^{242} \mathrm{Pu}$ & ${ }^{238} \mathrm{U}$ \\
\hline Number of moles & 41.6 & $2.0110^{-2}$ & $1.4010^{-2}$ & $2.0310^{-2}$ & 21.1 \\
\hline
\end{tabular}

Boundary conditions for the radionuclides are as follows:

- As given in Equation (19) above on the container boundary $\partial \mathcal{C}$;

- $C_{k}=0, k=-2,-1,1,2$ on the top and bottom sides of the elementary cell $R^{*}$;

- Periodic boundary conditions on the four outer vertical sides of $R^{*}$.

The simulation should cover a period of $10^{6}$ years.

\subsection{OUTPUT REQUIREMENTS}

The following output quantities are expected from the simulations (both tables and graphical representations):

- Total fluxes for all radionuclides on the top and bottom horizontal boundaries of $\mathcal{R}^{*}$, as a function of time;

- Total fluxes through the seal — backfilled drift interfaces, as a function of time;

- Total fluxes through the buffer - seal interfaces, as a function of time;

- Total fluxes through the backfilled drift — geological medium interfaces, as a function of time;

- Concentration profiles for all radionuclides along both symmetry planes, at times $10^{2}, 10^{3}, 5 \times 10^{2}, 10^{4}, 10^{5}, 10^{6}$ years;

- Total cumulative concentration of dissolved silica as a function of time;

- Exact time at which the total initial amount of silica has been dissolved;

- Total cumulative precipitation for each element and isotope, as a function of time. 
Table VI. General physical properties

\begin{tabular}{llcc}
\hline & $K(\mathrm{~m} / \mathrm{s})$ & $\phi(\%)$ & $\rho_{\mathrm{s}}$ \\
\hline buffer & $10^{-13}$ & 25 & 1.8 \\
backfilled drift & $10^{-9}$ & 40 & 2.1 \\
clay & $10^{-13}$ & 15 & 2.1 \\
\hline
\end{tabular}

Table VII. Physical properties for silica

\begin{tabular}{lcccc}
\hline & $d_{e}\left(\mathrm{~m}^{2} / \mathrm{s}\right)$ & $\alpha_{l}(\mathrm{~m})$ & $\alpha_{t}(\mathrm{~m})$ & $K_{d}\left(\mathrm{~m}^{3} / \mathrm{kg}\right)$ \\
\hline buffer & $510^{-11}$ & 0 & 0 & $10^{-4}$ \\
backfilled drift & $210^{-10}$ & 0 & 0 & $10^{-4}$ \\
clay & $510^{-11}$ & 0 & 0 & $10^{-4}$ \\
\hline
\end{tabular}

Table VIII. Physical properties for caesium

\begin{tabular}{lcccc}
\hline & $d_{e}\left(\mathrm{~m}^{2} / \mathrm{s}\right)$ & $\alpha_{l}(\mathrm{~m})$ & $\alpha_{t}(\mathrm{~m})$ & $K_{d}\left(\mathrm{~m}^{3} / \mathrm{kg}\right)$ \\
\hline buffer & $510^{-11}$ & 0 & 0 & $\mathrm{cf.}(12)$ \\
backfilled drift & $210^{-10}$ & 5 & 1 & $10^{-3}$ \\
clay & $510^{-11}$ & 5 & 1 & $10^{-3}$ \\
\hline
\end{tabular}

Table IX. Physical properties for plutonium

\begin{tabular}{lccccc}
\hline & $d_{e}\left(\mathrm{~m}^{2} / \mathrm{s}\right)$ & $\alpha_{l}(\mathrm{~m})$ & $\alpha_{t}(\mathrm{~m})$ & $K_{d}\left(\mathrm{~m}^{3} / \mathrm{kg}\right)$ & $C_{k}^{\text {sat }}(\mathrm{mol} / \mathrm{l})$ \\
\hline buffer & $510^{-11}$ & 0 & 0 & 3 & $410^{-9}$ \\
backfilled drift & $210^{-10}$ & 5 & 1 & $8.510^{-3}$ & $410^{-9}$ \\
clay & $510^{-11}$ & 5 & 1 & $8.510^{-3}$ & $410^{-9}$ \\
\hline
\end{tabular}

Table X. Physical properties for uranium

\begin{tabular}{lccclc}
\hline & $d_{e}\left(\mathrm{~m}^{2} / \mathrm{s}\right)$ & $\alpha_{l}(\mathrm{~m})$ & $\alpha_{t}(\mathrm{~m})$ & $K_{d}\left(\mathrm{~m}^{3} / \mathrm{kg}\right)$ & $C_{k}^{\text {sat }}(\mathrm{mol} / \mathrm{l})$ \\
\hline buffer & $510^{-11}$ & 0 & 0 & 3 & $210^{-9}$ \\
backfilled drift & $210^{-10}$ & 5 & 1 & $1.710^{-2}$ & $210^{-9}$ \\
clay & $510^{-11}$ & 5 & 1 & $1.710^{-2}$ & $210^{-9}$ \\
\hline
\end{tabular}




\subsection{PHYSICAL COEFFICIENTS}

It should be noted that the buffer and the seal are actually the same material.

\section{Couplex3: Coupling Near and Far-fields}

\subsection{Motivations}

The aim of that final test case is to use the results of the near-field computation (COUPLEX 2) to describe the behavior of the radionuclide source term, $f_{i}$, in the far-field computation (Couplex1, Equation (6)). In this way, we could include as much as possible of the repository behavior, coming from a near-field computation, inside the radionuclide source term $f_{i}$ necessary for a far-field simulation.

The coupling between the two simulations should then allow possible near-field / far-field feedbacks.

This test case was more open than the previous two, and the way the coupling should be carried out was not specified beforehand, and was left up to the participants.

The results of the Couplex 2 Test Case on a cell $\mathcal{R}^{*}$ (dimension 27 $\mathrm{m} \times 100 \mathrm{~m} \times 49.6 \mathrm{~m}$ ) have to be used to define the source behavior of the 2D repository $\mathcal{R}$ (dimension $3240 \mathrm{~m} \times 6 \mathrm{~m}$ ), as in figure 1 in Couplex 1 Section 2.2, and Equation (6). The simulation period is $T=10^{7}$ years, as in COUPLEX1.

The cell $\mathcal{R}^{*}$ in COUPLEX 2 was actually part of a larger repository and we assume for simplicity that the whole repository is made up of 10 parallel lines of containers. Each line of containers is made by repeating 120 times the backfilled drift / cells system described in Figure 4 in COUPLEX 2. The length of a line is then $3240 \mathrm{~m}$. All the lines belong to the same horizontal plane. The distance between two lines is $50 \mathrm{~m}$. The geometry is shown in Figure 6.

The radio-elements to be considered in the repository for the far-field computation are now those used in COUPLEX2, that is an isolated ${ }^{135} \mathrm{Cs}$ and two radionuclide chains of ${ }^{238} \mathrm{Pu}$ and ${ }^{242} \mathrm{Pu}$, as described in Section 3.4 (COUPLEX 2), following transport Equations (7) and (13)-(16) (Sections 3.3 and 3.4 in COUPLEX 2).

We are interested in the far-field simulation of a 2D vertical cross-section of the disposal site, similar to the one in the simulation of CoupLEX1. This cross-section is parallel to the lines of containers.

Data in Table II for Couplex 1 have to be completed by the ones in Tables VI-X for COUPLEX 2.

The host geological medium then becomes the clay layer defined for COUPLEX 1, but with the same porosity of $15 \%$ for all radionuclides. Other char- 


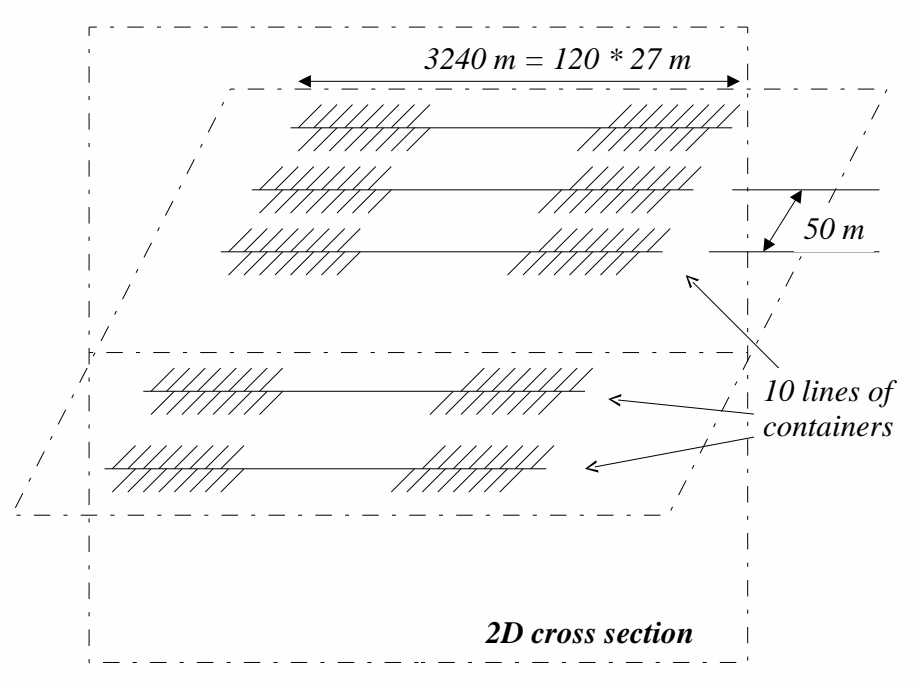

Figure 6. Geometry of the disposal site

acteristics of the clay are now the ones of the geological medium defined in Tables VIII-X for CoupleX 2 Section 3.6.

\subsection{OUTPUT REQUiREMENTS}

- At least one simulation using the same kind of sequential coupling as for COUPLEX 1 (the repository behavior is a simple input to the far-field simulation) should be carried out, and the results should be presented following the requirements mentioned in Section 2.6.

- If another coupling method has been chosen, the results should still be presented according to the requirements metioned in Section 2.6.

\section{Acknowledgements}

We wish to thank all of the teams who took part in the test cases for their very active participations. P. Bastian (IWR, Heidelberg), Ph. Ackerer, R. Mosé and H. Hotteit (IMFS, Strasbourg) made several remarks that helped to clarify the models as presented here.

The original version of this document was an "exercise" which was submitted to the scientific community by Andra (Agence Nationale pour la Gestion des Déchets Radioactifs - French National Radioactive Waste Management Agency) in January 2001, and lasted throughout that year. Results were 
presented by several teams during the Cemracs Summer School in Marseilles, in July 2001. We thank Andra for its financial support throughout the exercise.

\section{Appendix}

\section{A. Description of the data file for COUPLEX 1}

The file source. dat contains data needed to compute the source term $f_{i}$ in Equation (6). These data come from a near-field computation. The file has 212 lines, and each line contains three numbers $t^{p}, \tilde{f}_{1}^{p}, \tilde{f}_{2}^{p}, p=1, \ldots 212$, where $t^{p}$ is the time, and the source term $f_{i}\left(t^{p}\right)$ is related to $\tilde{f}_{i}^{p}$ by: $f_{i}\left(t^{p}\right)=$ $\tilde{f}_{i}^{p} / S$, where $S$ is the surface of the repository.

The times $t^{p}$ are in years, and the numbers $\tilde{f}_{i}^{p}$ are in units of moles /year.

\section{B. Conversion between activities and number of moles}

The activity (in becquerels) of a radionuclide is the number of disintegrations per second. The rule for converting the activity to a number of moles is simply:

$$
N=T /(\ln (2) \mathcal{N}) A
$$

$T$ being the half-life of the element (in seconds), and $\mathcal{N}$, Avogrado's number $\left(\mathcal{N}=6.0210^{23} \mathrm{~mol}^{-1}\right)$.

The initial activities for the various radionuclides are shown in Table XI. Numbers in the table apply to one package, and there are eight packages per cell.

Table XI. Radionuclide inventory per package

\begin{tabular}{cccccc}
\hline Isotope & ${ }^{135} \mathrm{Cs}$ & ${ }^{238} \mathrm{Pu}$ & ${ }^{234} \mathrm{U}$ & ${ }^{242} \mathrm{Pu}$ & ${ }^{238} \mathrm{U}$ \\
\hline Activity & $2.9910^{10}$ & $3.7910^{11}$ & $9.4710^{7}$ & $8.9410^{7}$ & $7.8110^{6}$ \\
\hline
\end{tabular}

\section{References}

Bear, J. and Y. Bachmat: 1991, Introduction to modeling of transport phenomena in porous media. Kluwer.

Bear, J. and A. Verruijt: 1987, Modeling Groundwater Flow and Pollution, Vol. 2 of Theory and Applications of Transport in Porous Media. Kluwer. 